\title{
MANAJEMEN RISIKO KECELAKAAN KERJA PADA KARYAWAN PT PELABUHAN INDONESIA IV (PERSERO) CABANG MAKASSAR
}

\section{WORK ACCIDENT RISK MANAGEMENT FOR EMPLOYEES OF PT PELABUHAN INDONESIA IV (PERSERO) MAKASSAR BRANCH}

\author{
Nunik Sulistyaningtyas ${ }^{1}$, M. Furqaan Naiem ${ }^{1}$, Muhammad Syafar ${ }^{2}$ \\ ${ }^{1}$ Bagian Kesker, Fakultas Kesehatan Masyarakat, Universitas Hasanuddin \\ ${ }^{2}$ Bagian Promosi Kesehatan, Fakultas Kesehatan Masyarakat, Universitas Hasanuddin \\ Email Korespondensi: tyasnunik673@yahoo.com
}

\begin{abstract}
ABSTRAK
Kurangnya kesadaran akan pentingnya mengelola risiko dan tidak adanya unit yang bertanggung jawab penuh terhadap risiko di cabang mengakibatkan masalah yang menghambat proses manajemen risiko. Penelitian ini bertujuan untuk evaluasi manajemen risiko kecelakaan kerja pada karyawan. Penelitian ini dilaksanakan di PT Pelabuhan Indonesia IV (Persero) Cabang Makassar. Penelitian ini merupakan penelitian observasi analitik dengan pendekatan cross sectional study. Populasi adalah keseluruhan karyawan Divisi Pelayanan Barang dan Aneka Usaha (PBAU) PT Pelabuhan Indonesia IV (Persero) Cabang Makassar. Sampel sebanyak 48 karyawan. Pengumpulan data melalui wawancara, observasi dan kuesioner. Data dianalisis secara univariat dan analisis risiko menggunakan matriks risiko berdasarkan standar AS/NZS 4360. Hasil penelitian menemukan 47 potensi bahaya. 4 potensi bahaya kategori risiko sangat tinggi, 27 potensi bahaya kategori risiko tinggi, 15 potensi bahaya kategori risiko medium dan 1 potensi bahaya kategori risiko rendah. Pengendalian risiko dengan administrative dan APD.
\end{abstract}

Kata kunci: penilaian risiko, tindakan tidak aman dan kondisi tidak aman, AS/NZS 4360

\begin{abstract}
The lack of awareness of the importance of risk managing and the absence of a unit that is fully responsible for risk in the branch produce in problems that hinder the risk management process. This study aims to evaluate the risk management of workplace accidents to employees. This research was carried out at PT Pelabuhan Indonesia IV (Persero) Makassar Branch. This research is an analytic observation research with cross sectional study approach. The population were all employees of the PT Pelabuhan Indonesia IV (Persero) Makassar Branch of Goods and Business Services Division (PBAU). The research samples were 48 employees. Data were collected through interviews, observations and questionnaires. Data were analyzed by univariate and risk analysis using a risk matrix based on AS / NZS 4360 standard. The result found there were 47 potential hazards. 4 potential hazards were very high risk categories, 27 potential hazards were high risk categories, 15 potential hazards were medium risk categories and 1 potential hazard was low risk category. Risk control by administrative and Personal Protective Equipment (PPE).
\end{abstract}

Keywords: Risk Assesment, Unsafe Actions and Unsafe Conditions, AS / NZS 4360 


\section{PENDAHULUAN}

Angka kecelakaan kerja merupakan suatu indikator keselamatan kerja di suatu perusahaan/industri. Industri dikatakan memiliki zero accident apabila tidak terdapat kecelakaan kerja. Zero Accident Award yang merupakan bagian dari program nasional pembudayaan K3 bertujuan untuk memberikan motivasi kepada perusahaan-perusahaan yang telah melaksanakan K3 dan berhasil mencapai nihil kecelakaan pada kurun waktu tertentu. Nihil kecelakaan yang dimaksud adalah dapat mencegah terjadinya kecelakaan kerja di tempat kerja tanpa kehilangan waktu/jam kerja (Salami, 2015).

Pelaksanaan keselamatan dan kesehatan kerja (K3) selain berkontribusi dalam mencegah kerugian dengan cara mempertahankan, meningkatkan status kesehatan dan kapasitas kerja fisik pekerja serta mencegah terjadinya cedera atau penyakit pada pekerja, tetapi juga berkontribusi dalam membentuk perilaku hidup sehat dan perilaku kerja yang kondusif bagi keselamatan dan kesehatan pekerja (Kurniawidjaja, L.M. 2015).

Mengingat hazards terdapat hampir di seluruh tempat kerja, maka upaya untuk mencegah dan mengurangi risiko yang mungkin timbul akibat dari proses pekerjaan perlu segera dilakukan. Melalui risk management process, risiko yang mungkin timbul dapat diidentifikasi, dinilai dan dikendalikan sedini mungkin melalui pendekatan preventif, inovatif dan partisipatif.
Manajemen potensi bahaya K3 bertujuan untuk menghilangkan atau mengurangi risiko kecelakaan dan sakit yang berhubungan dengan kerja. Manajemen keselamatan dan kesehatan kerja memerlukan suatu proses yang terdiri dari identifikasi hazards, penilaian risiko, pengendalian risiko dan evaluasi sarana pengendalian yang telah diimplementasikan (Tarwaka. 2017).

Pelabuhan menurut Peraturan Menteri Perhubungan RI Nomor : PM 51 Tahun 2015 tentang Penyelenggaraan Pelabuhan Laut adalah tempat yang terdiri atas daratan dan / atau perairan dengan batas-batas tertentu sebagai tempat kegiatan pemerintahan dan kegiatan pengusahaan yang dipergunakan sebagai tempat kapal bersandar, naik turun penumpang, dan/atau bongkar muat barang berupa terminal dan tempat berlabuh kapal yang dilengkapi dengan fasilitas keselamatan dan keamanan pelayaran dan kegiatan penunjang pelabuhan serta sebagai tempat perpindahan intra dan antarmoda transportasi.

Kegiatan pelayanan barang merupakan aktivitas terkritis dari seluruh lintasan kritis jejaring pelayanan kepelabuhanan. Bertolak dari posisi yang sangat kritis tersebut, maka penyelenggara pelabuhan atau operator terminal menaruh perhatian yang terpusat pada kegiatan bongkar muat. Makin cepat kegiatan bongkar muat, makin singkat waktu kapal di pelabuhan sehingga biaya labuh-tambat menjadi rendah 
(Lasse,D.A. 2016).

Penelitian Saragih, W.L dkk (2015) di Pelabuhan Teluk Nibung Tanjung Balai Asahan menunjukkan bahwa bahaya pada proses kerja stevedoring, bahaya tertinggi pada saat membuka terpal penutup barang di palka kapal. Bahaya yang paling dominan adalah bahaya tertabrak barang. Bahaya dominan pada proses cargodoring adalah posisi tubuh membungkuk ketika mengangkat barang. Sedangkan pada proses delivery terdapat bahaya jatuh dari ketinggian ketika menyusun barang di atas truk. Hasil evaluasi menunjukkan bahwa terdapat risiko bahaya high pekerjaan bongkar muat seperti tenggelam, tertabrak, dan jatuh dari ketinggian.

Pelaksanaan sistem manajemen risiko sampai tahun 2016 secara keseluruhan masih belum maksimal. Kendala yang dihadapi terutama pada proses assessment atau pengelolaan risiko di unit/cabang. Kurangnya kesadaran akan pentingnya mengelola risiko dan tidak adanya unit yang memiliki tugas khusus dan bertanggung jawab penuh terhadap risiko di cabang mengakibatkan masalah yang menghambat proses sistem manajemen risiko (Laporan Tahunan PT Pelabuhan Indonesia IV (Persero). 2016). Tujuan penelitian ini adalah untuk mengetahui manajemen risiko kecelakaan kerja pada karyawan PT. Pelabuhan Indonesia IV (Persero) Cabang Makassar.

\section{BAHAN DAN METODE}

\section{Lokasi}

Penelitian ini dilaksanakan di area operasional Pelayanan Barang yakni unit kerja bongkar muat barang di dermaga dan lapangan penumpukan PT. Pelindo IV (Persero) Cabang Makassar.

\section{Rancangan penelitian}

Jenis penelitian yang digunakan adalah penelitian observasi analitik yang menggunakan metode kuantitatif dengan pendekatan penelitian cross sectional study melalui wawancara, kuesioner dan oebservasi tentang manajemen risiko kecelakaan kerja pada karyawan PT. Pelabuhan Indonesia IV (Persero) Cabang Makassar.

\section{Populasi dan Sampel penelitian}

Populasi dalam penelitian ini adalah seluruh karyawan Divisi Pelayanan Barang dan Aneka Usaha (PBAU) PT. Pelabuhan Indonesia IV (Persero) Cabang Makassar yang berjumlah 55 orang. Sampel dalam penelitian ini berjumlah 48 karyawan. Sampel diambil berdasarkan tabel penentuan jumlah sampel yang dikembangkan oleh Isaac dan Michael untuk tingkat kesalahan $5 \%$ dengan jumlah populasi sebanyak 55 orang adalah jumlah sampelnya sebanyak 48 orang.

\section{Pengumpulan data dan Analisis Data}

Pengumpulan data dilakukan melalui wawancara kepada beberapa pihak untuk mendapatkan gambaran umum mengenai proses 
manajemen risiko, observasi langsung ke lokasi perusahaan dengan memperhatikan proses kerja dan melihat beberapa risiko yang mungkin menimbulkan kecelakaan kerja dan kuesioner yang dibagikan kepada karyawan. Kemudian dilakukan analisis data univariat yang dilanjutkan dengan analisis risiko.

\section{HASIL PENELITIAN}

Dalam penelitian ini diperoleh tindakan tidak aman (unsafe acts) yang paling berbahaya menurut karyawan adalah minum alcohol atau obat-obatan terlarang (91.7\%), sedangkan yang paling rendah adalah kesalahan dalam mengangkat (62.5\%). Kondisi tidak aman (unsafe conditions) yang paling berbahaya menurut karyawan adalah bahaya kebakaran dan ledakan (83.3\%), sedangkan yang paling rendah adalah pengamanan peralatan yang tidak cukup saat bekerja, peralatan dan material yang rusak, dan pemeliharaan dan inspeksi yang kurang baik yaitu sebesar $60.4 \%$ (pada tabel 1).

Penilaian risiko secara langsung pada karyawan didapatkan hasil bahwa tindakan tidak aman (unsafe acts) yang menurut karyawan berisiko terhadap pekerjaan bongkar muat yang paling tinggi adalah minum alkohol atau obatobatan terlarang (79.2\%). sedangkan yang paling rendah adalah kurang konsentrasi saat bekerja (62.5\%). Kondisi tidak aman (unsafe conditions) yang menurut karyawan berisiko terhadap pekerjaan bongkar muat yang paling tinggi adalah bahaya kebakaran dan ledakan (72.9\%), sedangkan yang paling rendah adalah kondisi udara yang berbahaya (62.5\%) (pada tabel 2).

Evaluasi risiko pada karyawan dilakukan untuk mengetahui sejauh mana pengetahuan karyawan mengenai risiko jika terjadi kecelakaan karena tindakan tidak aman (unsafe acts) dan kondisi yang tidak aman (unsafe conditions) pada pekerjaan bongkar muat. Sebanyak 33 karyawan (68.8\%) menyatakan risiko jika terjadi kecelakaan karena menggunakan alat yang sudah rusak dan risiko jika terjadi kecelakaan karena menggunakan peralatan dengan tidak semestinya merupakan risiko yang tidak dapat diterima karena dapat mengakibatkan cedera serius dan kematian.

Hasil analisis risiko dengan menggunakan form JSA ditemukan 47 potensi bahaya dari 4 tahapan pekerjaan bongkar muat. Penilaian risiko pekerjaan bongkar muat menggunakan risk matriks didapatkan 4 potensi bahaya kategori risiko sangat tinggi, 27 potensi bahaya kategori risiko tinggi, 15 potensi bahaya kategori risiko medium dan 1 potensi bahaya kategori risiko rendah (pada tabel 3). 
Tabel 1 Distribusi Frekuensi Tindakan Tidak Aman dan Kondisi Tidak Aman yang Berbahaya terhadap Pekerjaan Bongkar Muat

\begin{tabular}{|c|c|c|c|}
\hline \multirow[t]{2}{*}{ No. } & \multirow[t]{2}{*}{ Penyebab Kecelakaan } & \multicolumn{2}{|c|}{ Jumlah } \\
\hline & & $\mathrm{n}$ & $\%$ \\
\hline A. & Tindakan tidak aman & & \\
\hline \multirow[t]{3}{*}{1} & Menggunakan alat yang sudah rusak & & \\
\hline & Berbahaya & 37 & 77.1 \\
\hline & Tidak berbahaya & 11 & 22.9 \\
\hline \multirow[t]{3}{*}{2} & Menggunakan peralatan dengan tidak semestinya & & \\
\hline & Berbahaya & 35 & 72.9 \\
\hline & Tidak berbahaya & 13 & 27.1 \\
\hline \multirow[t]{3}{*}{3} & Mengangkut atau menempatkan barang dengan tidak benar & & \\
\hline & Berbahaya & 35 & 72.9 \\
\hline & Tidak berbahaya & 13 & 27.1 \\
\hline \multirow[t]{3}{*}{4} & Kesalahan dalam mengangkat & & \\
\hline & Berbahaya & 30 & 62.5 \\
\hline & Tidak berbahaya & 18 & 37.5 \\
\hline \multirow[t]{3}{*}{5} & Memperbaiki alat ketika peralatan sedang dijalankan & & \\
\hline & Berbahaya & 31 & 64.6 \\
\hline & Tidak berbahaya & 17 & 35.4 \\
\hline \multirow[t]{3}{*}{6} & Minum alcohol atau obat terlarang & & \\
\hline & Berbahaya & 44 & 91.7 \\
\hline & Tidak berbahaya & 4 & 8.3 \\
\hline \multirow[t]{3}{*}{7} & Kurang konsentrasi saat bekerja & & \\
\hline & Berbahaya & 36 & 75 \\
\hline & Tidak berbahaya & 12 & 25 \\
\hline \multirow[t]{2}{*}{ B } & Kondisi tidak aman & & \\
\hline & Peralatan dan material & & \\
\hline \multirow[t]{3}{*}{1} & Pengamanan peralatan yang tidak cukup saat bekerja & & \\
\hline & Berbahaya & 29 & 60.4 \\
\hline & Tidak berbahaya & 19 & 39.6 \\
\hline \multirow[t]{3}{*}{2} & Peralatan dan material yang rusak & & \\
\hline & Berbahaya & 29 & 60.4 \\
\hline & Tidak berbahaya & 19 & 39.6 \\
\hline \multirow[t]{3}{*}{3} & $\begin{array}{l}\text { Mesin dan peralatan yang tidak dilengkapi pengaman saat } \\
\text { bekerja }\end{array}$ & & \\
\hline & Berbahaya & 38 & 79.2 \\
\hline & Tidak berbahaya & 10 & 20.8 \\
\hline \multirow[t]{4}{*}{4} & Pemeliharaan dan inspeksi yang kurang baik & & \\
\hline & Berbahaya & 29 & 60.4 \\
\hline & Tidak berbahaya & 19 & 39.6 \\
\hline & Lingkungan kerja & & \\
\hline \multirow[t]{3}{*}{5} & Tempat kerja yang sangat berdesakan & & \\
\hline & Berbahaya & 30 & 62.5 \\
\hline & Tidak berbahaya & 18 & 37.5 \\
\hline \multirow[t]{4}{*}{6} & Bahaya kebakaran dan ledakan & & \\
\hline & Berbahaya & 40 & 83.3 \\
\hline & Tidak berbahaya & 8 & 16.7 \\
\hline & Tata cara kerja & & \\
\hline \multirow[t]{3}{*}{7} & Kurangnya pelatihan & & \\
\hline & Berbahaya & 34 & 70.8 \\
\hline & Tidak berbahaya & 14 & 29.2 \\
\hline
\end{tabular}




\section{Tabel 2 Distribusi Frekuensi Tindakan Tidak Aman dan Kondisi Tidak Aman yang Berisiko pada} Pekerjaan Bongkar Muat

\begin{tabular}{|c|c|c|c|}
\hline \multirow{2}{*}{ No } & \multirow{2}{*}{ Penyebab Kecelakaan } & \multicolumn{2}{|c|}{ Jumlah } \\
\hline & & n & $\%$ \\
\hline $\mathbf{A}$ & Tindakan tidak aman & & \\
\hline \multirow[t]{3}{*}{1} & Menggunakan alat yang sudah rusak & & \\
\hline & Berisiko & 34 & 70.8 \\
\hline & Tidak berisiko & 14 & 29.2 \\
\hline \multirow[t]{3}{*}{2} & Minum alkohol atau obat-obatan terlarang & & \\
\hline & Berisiko & 38 & 79.2 \\
\hline & Tidak berisiko & 10 & 20.8 \\
\hline \multirow[t]{3}{*}{3} & Kurang konsentrasi saat bekerja & & \\
\hline & Berisiko & 30 & 62.5 \\
\hline & Tidak berisiko & 18 & 37.5 \\
\hline \multirow[t]{2}{*}{ B } & Kondisi tidak aman & & \\
\hline & Peralatan dan material & & \\
\hline \multirow[t]{4}{*}{1} & $\begin{array}{l}\text { Mesin dan peralatan yang tidak dilengkapi pengaman saat } \\
\text { bekerja }\end{array}$ & & \\
\hline & Berisiko & 33 & 68.8 \\
\hline & Tidak berisiko & 15 & 31.3 \\
\hline & Lingkungan kerja & & \\
\hline \multirow[t]{3}{*}{2} & Bahaya kebakaran dan ledakan & & \\
\hline & Berisiko & 35 & 72.9 \\
\hline & Tidak berisiko & 13 & 27.1 \\
\hline \multirow[t]{3}{*}{3} & Kondisi udara yang berbahaya & & \\
\hline & Berisiko & 30 & 62.5 \\
\hline & Tidak berisiko & 18 & 37.5 \\
\hline
\end{tabular}

Tabel 3 Hasil Penghitungan Tingkat Risiko pada Kegiatan Bongkar Muat Barang

\begin{tabular}{|c|c|c|c|c|c|c|}
\hline \multirow[t]{2}{*}{ No. } & \multirow[t]{2}{*}{ Aktivitas / Area } & \multirow[t]{2}{*}{ Potensi bahaya } & \multirow[t]{2}{*}{ Konsekuensi } & \multicolumn{3}{|c|}{ Risk Matriks } \\
\hline & & & & $\mathbf{C}$ & $\mathbf{L}$ & $\mathbf{R R}$ \\
\hline 1 & $\begin{array}{l}\text { Persiapan awal } \\
\text { pekerjaan }\end{array}$ & & & & & \\
\hline \multirow[t]{2}{*}{$\mathrm{a}$} & $\begin{array}{c}\text { Pengecekan alat / } \\
\text { bengkel } \\
\text { pemeliharaan }\end{array}$ & $\begin{array}{l}\text { Kurang teliti dalam } \\
\text { pengecekan }\end{array}$ & $\begin{array}{l}\text { Alat tdak dapat } \\
\text { berfungsi dengan } \\
\text { maksimal }\end{array}$ & 3 & 2 & $\mathrm{H}$ \\
\hline & & $\begin{array}{c}\text { Kurang ahli dalam } \\
\text { penanganan alat }\end{array}$ & $\begin{array}{c}\text { Alat tdak dapat } \\
\text { berfungsi dengan baik }\end{array}$ & 3 & 2 & $\mathrm{H}$ \\
\hline $\mathrm{b}$ & $\begin{array}{l}\text { Safety briefing } \\
\text { sebelum } \\
\text { melakukan } \\
\text { pekerjaan }\end{array}$ & $\begin{array}{c}\text { Keterbatasan } \\
\text { informasi }\end{array}$ & $\begin{array}{c}\text { Pekerja tidak } \\
\text { memahami potensi } \\
\text { bahaya pekerjaannya }\end{array}$ & 1 & 2 & M \\
\hline 2 & Stevedoring & & & & & \\
\hline \multirow[t]{6}{*}{ a } & $\begin{array}{l}\text { Membongkar } \\
\text { barang dari } \\
\text { dek/palka ke } \\
\text { dermaga atau } \\
\text { sebaliknya }\end{array}$ & $\begin{array}{l}\text { Terjatuh ke dalam } \\
\text { palka }\end{array}$ & Luka, patah tulang & 3 & 2 & $\mathrm{H}$ \\
\hline & & Jatuh ke laut & Tenggelam, Kematian & 3 & 1 & M \\
\hline & & Terpeleset & Luka, cidera & 3 & 2 & $\mathrm{H}$ \\
\hline & & Tersandung & Luka, patah tulang & 3 & 2 & $\mathrm{H}$ \\
\hline & & $\begin{array}{l}\text { Terpapar sinar } \\
\text { matahari }\end{array}$ & Dehidrasi, kelelahan & 1 & 4 & $\mathrm{M}$ \\
\hline & & Terpapar debu & $\begin{array}{l}\text { Gangguan pernapasan, } \\
\text { iritasi mata }\end{array}$ & 3 & 1 & M \\
\hline
\end{tabular}




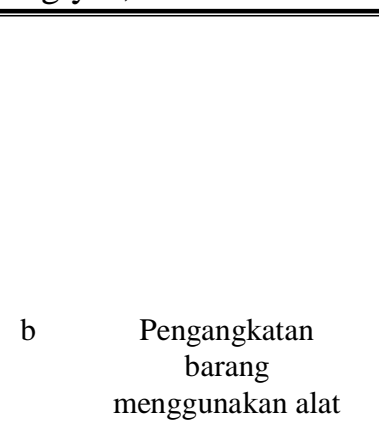
$3 \quad$ Cargodoring Mengeluarkan barang dari sling di atas dermaga / melepas sling

b

$$
\begin{gathered}
\text { Mengangkat dari } \\
\text { dermaga, } \\
\text { mengangkut } \\
\text { kemudian } \\
\text { menyusun barang } \\
\text { di gudang atau } \\
\text { lapangan } \\
\text { penumpukan }
\end{gathered}
$$

4 Receiving / delivery (gudang /

lapangan penumpukan Memindahkan barang dari gudang atau lapangan

\section{Tertimpa barang \\ Tertabrak alat \\ Cuaca hujan, angin \\ kencang \\ Kelelahan \\ Operator tidak memiliki SIO}

\section{Sling putus}

Operator lalai/ kurang

konsentrasi

Terjepit alat

Terpeleset

Tersandung

Cuaca hujan, angin deras

Jam kerja panjang

\section{Bising}

Terpeleset

Tertimpa barang Terjepit alat angkat Tersandung Terpapar sinar matahari

Terpapar debu

Operator tidak memiliki SIO (Surat Ijin Operator)

\section{Forklift tidak} memiliki SILO (Surat Ijin Layak Operasi) Kelebihan muatan

Paparan debu

\begin{tabular}{|c|c|c|}
\hline $\begin{array}{c}\text { Cidera, patah tulang, } \\
\text { kematian }\end{array}$ & 5 & 1 \\
\hline $\begin{array}{l}\text { Luka, cidera, patah } \\
\text { tulang }\end{array}$ & 3 & 2 \\
\hline terpeleset & 2 & 2 \\
\hline $\begin{array}{l}\text { Kesalahan dalam } \\
\text { mengangkat }\end{array}$ & 3 & 2 \\
\hline $\begin{array}{l}\text { Operator berpotensi } \\
\text { menyebabkan } \\
\text { kecelakaan kerja }\end{array}$ & 4 & 2 \\
\hline $\begin{array}{c}\text { Luka, patah tulang, } \\
\text { kematian }\end{array}$ & 4 & 3 \\
\hline Barang jatuh kelaut & 1 & 2 \\
\hline Luka, patah tulang & 3 & 3 \\
\hline Luka, cidera & 2 & 2 \\
\hline Luka, cidera & 2 & 2 \\
\hline $\begin{array}{l}\text { Alat tidak terkendali, } \\
\text { barang jatuh }\end{array}$ & 5 & 3 \\
\hline $\begin{array}{c}\text { Kelelahan, kurang } \\
\text { konsentrasi }\end{array}$ & 2 & 4 \\
\hline Gangguan pendengaran & 2 & 2 \\
\hline Luka, patah tulang & 3 & 2 \\
\hline
\end{tabular}

Jam kerja panjang Terjatuh

Tertimpa barang Operator tidak fokus

Tertabrak

Operator tidak memiliki SIO

$\begin{array}{cccc}\text { Kematian } & 5 & 1 & \mathrm{H} \\ \text { Luka, patah tulang } & 3 & 3 & \mathrm{H} \\ \quad \text { Luka, cidera } & 2 & 2 & \mathrm{M} \\ \text { Dehidrasi, kelelahan } & 1 & 4 & \mathrm{M} \\ \begin{array}{c}\text { Gangguan pernapasan, } \\ \text { iritasi mata }\end{array} & 3 & 1 & \mathrm{M} \\ \begin{array}{c}\text { Operator berpotensi } \\ \text { menyebabkan }\end{array} & 4 & 2 & \mathrm{H} \\ \text { kecelakaan kerja } & & & \end{array}$

$\begin{array}{clll}\begin{array}{c}\text { Alat tidak layak } \\ \text { digunakan }\end{array} & 3 & 4 & \mathrm{E}\end{array}$

Forklift miring, $\quad 3 \quad 3 \quad$ H

Gangguan pernapasan, $\quad 3 \quad 1 \quad$ M iritasi mata Kelelahan

$\begin{array}{cccc}\text { Luka, cidera } & 3 & 2 & \mathrm{H}\end{array}$

$\begin{array}{llll}\text { Barang jatuh } & 2 & 3 & \mathrm{H}\end{array}$

Luka, patah tulang $\quad 3 \quad 3 \quad$ H 


\begin{tabular}{|c|c|c|c|c|c|c|c|}
\hline & & $\begin{array}{l}\text { ukan ke } \\
\text { uk atau } \\
\text { iknya }\end{array}$ & & & & & \\
\hline & & & $\begin{array}{c}\text { Alat forklift / RS } \\
\text { tidak memiliki SILO } \\
\text { (Surat Ijin Layak } \\
\text { Operasi) }\end{array}$ & $\begin{array}{c}\text { Alat tidak layak } \\
\text { digunakan }\end{array}$ & 3 & 4 & $\mathrm{E}$ \\
\hline & & & Terpapar debu & $\begin{array}{c}\text { Gangguan pernapasan, } \\
\text { iritasi mata }\end{array}$ & 3 & 1 & M \\
\hline & & & Kebisingan & Gangguan pendengaran & 2 & 2 & M \\
\hline & & & Getaran & Gangguan saraf & 3 & 2 & $\mathrm{H}$ \\
\hline & & & $\begin{array}{c}\text { Kesalahan dalam } \\
\text { mengangkat }\end{array}$ & Barang jatuh & 3 & 2 & $\mathrm{H}$ \\
\hline & & & $\begin{array}{l}\text { Posisi barang tidak } \\
\text { tepat pada } \\
\text { penumpukan }\end{array}$ & Barang jatuh & 3 & 2 & $\mathrm{H}$ \\
\hline & & & $\begin{array}{l}\text { Kelebihan muatan } \\
\text { pada alat maupun } \\
\text { truck }\end{array}$ & $\begin{array}{l}\text { Hilang keseimbangan } \\
\text { dan terguling }\end{array}$ & 3 & 3 & $\mathrm{H}$ \\
\hline & & & $\begin{array}{c}\text { Operator kurang } \\
\text { pelatihan }\end{array}$ & $\begin{array}{c}\text { Tertabrak benda/ } \\
\text { barang }\end{array}$ & 3 & 3 & $\mathrm{H}$ \\
\hline & & & Terjatuh & Luka, patah tulang & 3 & 2 & $\mathrm{H}$ \\
\hline & & & $\begin{array}{l}\text { Paparan sinar } \\
\text { matahari }\end{array}$ & Dehidrasi, kelelahan & 1 & 4 & M \\
\hline Keterangan: & $\mathrm{C}$ & $=$ Cons & ncy / Keparahan & & & & \\
\hline & $\mathrm{L}$ & $=$ Likel & d / Kemungkinan & & & & \\
\hline & RR & $=$ Risk $\mathrm{I}$ & gking / Peringkat Risiko & & & & \\
\hline
\end{tabular}

\section{PEMBAHASAN}

Manajemen risiko kecelakaan kerja pada karyawan PT Pelabuhan Indonesia IV (Persero) Cabang Makassar yang dilakukan melalui observasi dengan menggunakan form JSA (Job Safety Analysis) didapatkan hasil bahwa dari 4 (empat) tahapan pekerjaan bongkar muat ditemukan 47 potensi bahaya dengan jumlah potensi bahaya risiko tinggi jumlahnya lebih banyak (27 potensi bahaya risiko tinggi) daripada potensi bahaya risiko medium (15 potensi bahaya risiko medium) dan potensi bahaya risiko rendah (1 potensi bahaya risiko rendah).

Bahaya fisik dari kegiatan bongkar muat meliputi getaran, bising, paparan sinar matahari, angin kencang dan hujan. Bahaya kimia berasal dari debu yang ada di gudang dan lapangan penumpukan yang dapat menyebabkan gangguan pernapasan dan iritasi mata. Kesadaran akan keselamatan kerja pada karyawan tersebut ditunjukkan pada urutan tertinggi hasil identifikasi bahaya pada karyawan berdasarkan penyebab kecelakaan yaitu minum alcohol atau obat-obatan terlarang (91.7\%), bahaya kebakaran dan ledakan $(83.3 \%)$ dan mesin dan peralatan yang tidak dilengkapi pengaman (79.2\%).

Hasil identifikasi bahaya pada karyawan yang dapat menyebabkan kecelakaan selain item di atas adalah kurangnya pelatihan (70.8\%). Menurut Smith dan Sonesh (2011) dalam Waruwu, S. (2016) dikatakan bahwa pelatihan kesehatan dan keselamatan kerja (K3) dapat menurunkan risiko kecelakaan kerja. Semakin besar pengetahuan karyawan tentang K3 maka semakin kecil risiko terjadinya kecelakaan kerja, begitu juga sebaliknya. 
Penilaian risiko dengan menggunakan matriks risiko didapatkan hasil bahwa terdapat 4 potensi bahaya kategori risiko sangat tinggi, 27 potensi bahaya kategori risiko tinggi, 15 potensi bahaya kategori risiko medium dan 1 potensi bahaya kategori risiko rendah. Sejalan dengan penelitian Prasetio, D.B.(2016) pada pekerjaan bongkar muat di Pelabuhan Nusantara Tanjung Emas Semarang didapatkan hasil bahwa potensi bahaya yang teridentifikasi sebagai bahaya risiko tinggi jumlahnya lebih banyak (19 bahaya risiko tinggi) daripada bahaya risiko rendah (4 bahaya risiko rendah).

Penilaian risiko pada setiap tahapan kegiatan bongkar muat merupakan salah satu tindakan pencegahan untuk mengurangi risiko kecelakaan pada pekerja bongkar muat yang mengacu pada peraturan tentang keselamatan kerja seperti UU No. 1 tahun 1970 tentang Keselamatan Kerja.

Proses selanjutnya dari manajemen risiko kecelakaan adalah upaya pengendalian risiko pada setiap proses pekerjaan. Upaya pengendalian sesuai dengan ISO 31000:2009 dengan urutan eliminasi, substitusi, pengendalian teknik, administrasi dan alat pelindung diri. Upaya pengendalian risiko yang dilakukan perusahaan dalam prosedur penggunaan alat yaitu adanya kebijakan mengenai lisensi K3 pada operator pesawat angkat angkut dimana pekerja yang mengoperasikan alat berat harus memiliki SIO (Surat Ijin Operator), hal tersebut sesuai dengan Permenakertrans nomor PER.09/MEN/VII/2010 tentang operator dan petugas pesawat angkat angkut.

Safety briefing yang dilakukan setiap pagi sebelum melakukan pekerjaan merupakan salah satu pengendalian risiko, yang menjelaskan mengenai bahaya, pengendalian dan sikap kerja yang aman di tempat kerja. Pemberian safety induction yang dilakukan oleh perusahaan sesuai dengan Undang-Undang Keselamatan Kerja No. 1 Tahun 1970 pasal 9 yang mewajibkan pengurus menunjukkan dan menjelaskan pada tenaga kerja baru tentang kondisi dan bahaya, pengamanan dan alat-alat perlindungan serta cara dan sikap yang aman saat bekerja. Pengendalian risiko lain yang dapat dilakukan adalah memasang rambu-rambu keselamatan dan pembagian shift kerja dan rotasi kerja.

Alat pelindung diri (APD) merupakan pengendalian terakhir dimana pengendalian sebelumnya masih menyisakan risiko tinggi pada kecelakaan, tetapi pada pelaksanaan di lapangan alat pelindung diri merupakan pengendalian yang utama. Upaya pengendalian risiko yang dapat dilakukan terkait APD adalah inspeksi K3 harian untuk pemakaian APD lengkap dan memperketat pengawasan manajemen terhadap pekerja yang tidak memakai APD.

\section{KESIMPULAN DAN SARAN}

Berdasarkan hasil penelitian ini manajemen risiko kecelakaan kerja pada karyawan PT Pelabuhan Indonesia IV (Persero) Cabang Makassar yaitu identifikasi potensi bahaya kecelakaan dengan menggunakan form JSA ditemukan 47 potensi bahaya dari 4 tahapan pekerjaan bongkar muat. Penilaian risiko 
pekerjaan bongkar muat menggunakan risk matriks didapatkan 4 potensi bahaya kategori risiko sangat tinggi, 27 potensi bahaya kategori risiko tinggi, 15 potensi bahaya kategori risiko medium dan 1 potensi bahaya kategori risiko rendah. Pengendalian risiko yang dapat dilakukan adalah pengendalian administrative seperti sertifikasi operator alat (SIO), safety briefing dan pengawasan rutin setiap hari. Pengendalian dengan APD meliputi pengadaan safety shoes, safety helmet, masker dan rompi. Memberikan reward dan punishment pada pekerja di lapangan sebagai salah satu upaya untuk memotivasi pekerja agar mematuhi peraturan-peraturan yang berlaku terutama mengenai K3.Membuat pencatatan dan pelaporan yang khusus mengenai K3 sehingga dapat digunakan sebagai acuan / rekomendasi dalam perubahan yang diperlukan untuk menghindari kecelakaan kerja di masa mendatang. Komitmen manajemen untuk melakukan audit secara periodik terutama mengenai usaha-usaha keselamatan kerjanya dan membentuk unit khusus yang bertanggung jawab penuh terhadap risiko di cabang.

\section{DAFTAR PUSTAKA}

Depnaker RI. (1970). Undang-Undang No. 1 Tahun 1970 tentang Keselamatan Kerja. Jakarta: Departemen Tenaga Kerja RI.

Kurniawidjaja, L.M. (2015). Teori Dan Aplikasi Kesehatan Kerja. Jakarta:UIPRESS.

Lasse, D.A. (2016). Manajemen Kepelabuhanan. Jakarta: Rajawali Pers.
Laporan Tahunan PT. Pelabuhan Indonesia IV (Persero) tahun 2016. Grow with The Hinterland for Eastern Indonesia Economy Acceleration.

Peraturan Menteri Perhubungan RI Nomor : PM 51 Tahun 2015 tentang Penyelenggaraan Pelabuhan Laut.

Prasetio, D.B. (2016). Risk Assesment Pekerjaan Bongkar Muat Di Pelabuhan Nusantara Tanjung Emas Semarang. The 4 University Research Coloquium 2016.

Salami. (2015). Kesehatan Dan Keselamatan Lingkungan Kerja. Yogyakarta: Gadjah Mada University Press.

Saragih, W.L dkk. (2015). Penilaian Risiko Kecelakaan Kerja Pada Tenaga Kerja Bongkar Muat di Pelabuhan Teluk Nibung Tanjung Balai Asahan Tahun 2015.

Sugiyono. (2013). Metode Penelitian Manajemen. Bandung: Alfabeta.

Tarwaka. (2017). Keselamatan Dan Kesehatan Kerja, Manajemen Dan Implementasi K3 Di Tempat Kerja. Surakarta: Harapan Press.

Waruwu, S. (2016). Analisis Faktor K3 Yang Mempengaruhi Kecelakaan KerjaProyek Apartemen. 